\title{
SOME STRATEGIES TO IMPROVE THE LEARNING PROCESS
}

\author{
Beatriz Amante García ${ }^{1}$, María Martínez Martínez ${ }^{2}$ iD \\ ${ }^{1}$ Projectes d'Enginyeria, Universitat Politècnica de Catalunya, ${ }^{2}$ Enginyeria Química, Universitat \\ Politècnica de Catalunya, Barcelona/Spain \\ beatriz.amante@upc.edu, rosario.martinez@upc.edu
}

This last issue of JOTSE's volume 7 focuses on the diverse teaching/learning strategies being carried out in several universities worldwide. In this sense, our current issue reflects that no matter the continent nor the subject being taught the teaching staff is always concerned with students' learning process in their classrooms and that is why they do research on a wide range of strategies that could possibly favour such learning process as well as motivate their students.

The strategies proposed in the following articles range from introducing the concept of problem solving promoting creativity and developing this key skill as it is the experience presented in our first contribution by Renato Vizioli and Paulo Carlos Kaminski, lecturers at the Polytechnic University of São Paulo (USP) Brazil. More precisely, in this article "Problem definition as a stimulus to the creative process: Analysis of a classroom exercise" the teaching innovation experience is focused on a continuous training programme (PECE's MBA in Product and Service Management and Engineering (Escola Politécnica da USP) that the University of São Paulo offers to prepare professionals in Project Management so as to be able to develop products and services or innovative businesses. By using some relatively simple and readily available tools, a group of designers involved in a project can stimulate creativity from the outset in order to obtain a better solution to a problem. These tools must be used simultaneously throughout the creative and development process as the environment changes during the project and new variables are included, which influence even the definition of objectives. The selection of one path over another, or the appropriate balance in the use of different approaches, 
hinges on a design strategy, the corporate environment, and a series of specific deciding factors for each context.

In the second article, the strategy proposed is based on the use of the new technologies. Many authors agree with the idea that to enhance and increase students' learning it is necessary to motivate them. Such motivation could be reached by involving students themselves in their own assessment through the use of the new technologies. In this second article "Initiatives to foster engineering student motivation: A case study", the lecturers Encarnación Reyes, Alejandro Enfedaque and Jaime C. Gálvez present the case of two subjects in the degree of Civil Engineering in the Universidad Politécnica de Madrid (UPM), (Spain), in other words, The Construction and Building Materials I \& II, in which they have been steadily introducing innovation in the evaluation. As a matter of fact, this study covers the last three academic years when the Course Management System (CMS) of the modular object-oriented dynamic learning environment (Moodle) platform facilitated the implementation of several assessment activities including self and co-evaluation as well as the corresponding feedback (involved). Results show that over $70 \%$ of the students thought that the use of the Moodle platform and other teaching and assessment techniques had motivated them. In particular, the students highlighted the use of cooperative learning with $86 \%$ feeling that it helped them to learn.

The application of conceptual mapping development is a strategy that has been used in a subject for two consecutive academic years and it is presented in the following article: "Meaningful learning using concept maps as a learning strategy" by Maria Del Carmen Romero, Moisés Cazorla and Olga Buzón from the Universidad Internacional de la Rioja (Spain). This strategy has shown that it both contributes to the development of the learning to learn skill and to personal autonomy and initiative to improve the teaching-learning process. In this article, besides from the methodology used the conceptual mapping assessment rubric is also presented and discussed. Results were positive for academic achievement and students' satisfaction.

In the following article:"Differences in styles of thinking 'In Light of Sternberg's Theory': A Case Study of Different Educational Levels in Saudi Arabia”, Nahla Aljojo from King Abdulaziz University (Saudi Arabia) argues that knowing students' style of thinking could be a good strategy to aid and develop their learning. The study is based on the use of Sternberg Thinking Style Inventory (TSI) (Arabic version), this theory leads to understanding the differences in the way people think and it helps teachers to understand the student's ability at different levels of Education. 120 students were randomly selected from high schools, intermediate schools and 
universities participated in this study. 72 female and 48 male students from different educational backgrounds across Saudi Arabia filled in a questionnaire. The subjects were aged 15-25. In addition, the comparison between Saudi Arabian male and female thinking styles shows a significant difference according to gender.

In our last article "Exploring the Importance of Soft and Hard Skills as Perceived by IT Internship Students and Industry: a Gap Analysis" submitted by Frederick Patacsil, lecturer from the Pangasinan State University - Urdaneta City Campus (Filipinas), it is presented a strategy to improve students' employability within Information Technology Education (ITE) in the Philippines as this is a key issue in the country. In this article, the possibility of taking advantage of the training program (internship program) to survey potential employers and students themselves is explored. The aim is to detect the possible deficiencies that remain crucial for the industry sector. The results of the current study show that soft skills, for example, teamwork and interpersonal skills were the most relevant, which means that these are the skills most needed by students to improve. Soft skills are more important than technical skills as perceived by the industry and students, especially for the companies that are involved in providing customer services. Finally, we would like to thank the altruistic work carried out by both our reviewers and our Editorial Committee in JOTSE (Editorial team, Editorial Board \& reviewers) as they make the publishing of quality articles in all our JOTSE volumes possible.

We hope that you enjoy reading the articles included in the current volume/issue.

Published by OmniaScience (www.omniascience.com)

Journal of Technology and Science Education, 2017 (www.jotse.org)

Article's contents are provided on an Attribution-Non Commercial 3.0 Creative commons license. Readers are allowed to copy, distribute and communicate article's contents, provided the author's and JOTSE journal's names are included. It must not be used for commercial purposes. To see the complete licence contents, please visit http://creativecommons.org/licenses/by-nc/3.0/es/
} 